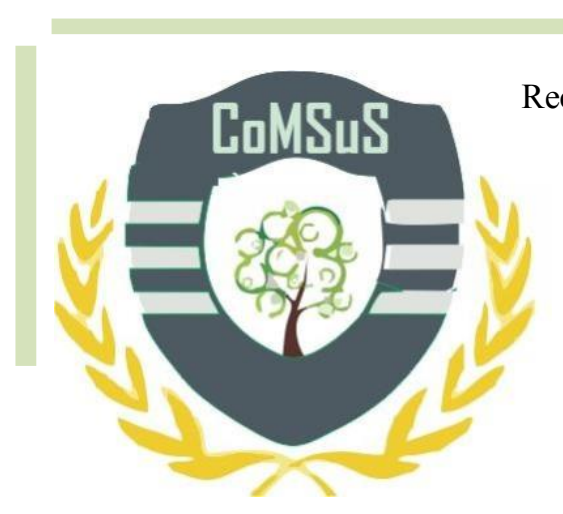

Recebido em 03/01/2018. Aprovado em 07/06/2018. Publicado em 08/11/2018.

Editor: Dr. Ivano Ribeiro

Processo de Avaliação: Double Blind Review - SEER/OJS

e-ISSN: $2359-5876$

https://doi.org/10.5935/2359-5876.20180002

\title{
PUBLICIDADE: UM ESTUDO BIBLIOMÉTRICO SOBRE O ESTADO DA ARTE
}

\author{
ADVERTISING: A BIBLIOMETRIC STUDY ON THE STATE OF ART
}

\author{
Carla Diniz Naue ${ }^{1}$ \\ Fabiane Favretto ${ }^{2}$ \\ Carline Ternus ${ }^{3}$
}

\begin{abstract}
RESUMO
A presente pesquisa tem como objetivo realizar um mapeamento bibliométrico sobre os principais estudos acerca do termo publicidade na base de dados Spell, caracteriza-se como um estudo descritivo, tendo por base uma pesquisa bibliométrica. Na busca, 61 artigos foram encontrados e trouxeram as seguintes análises: na maioria dos estudos utilizou-se do método qualitativo; apenas quatro autores tiveram destaque nas publicações e mais uma quantidade significativa de outros pesquisadores estudam sobre o tema, mostrando sua ascensão; a USP foi a IES que obteve maior destaque na produção científica neste tema; a maioria dos artigos tiveram suas publicações no ano de 2010, porém, nas buscas apareceram artigos desenvolvidos já no ano de 1979; marketing é o constructo mais utilizado nos estudos base. A partir da presente pesquisa, conclui-se que o estudo acerca da publicidade já está consolidado. Entretanto, as análises relacionando com a cultura ainda se apresentam uma lacuna. Este estudo buscará contribuir para possíveis pesquisas, para compreender a interferência da cultura na publicidade.
\end{abstract}

Palavras-chave: Publicidade; Cultura; Estudo bibliométrico.

\begin{abstract}
The present research aims to perform a bibliometric mapping on the main studies about the term advertising in the Spell database, is characterized as a descriptive study, based on a bibliometric research. In the search, 61 articles were found and the following analyzes were carried out: most of the studies used the qualitative method; only four authors were featured in the publications and a significant number of other researchers studied the subject, showing their rise; the USP was the IES that got more prominence in the scientific production in this subject; most of the articles had their publications in the year of 2010, however, in the search they appeared articles developed already in the year of 1979; marketing is the most used construct in baseline studies. From the present research, it is concluded that the study about advertising is already consolidated. However, the analyzes relating to culture still present a gap. This study will seek to contribute to possible research, to understand the interference of culture in advertising.
\end{abstract}

Keywords: Advertising; Culture; Bibliometric study.

\footnotetext{
${ }^{1}$ Bacharel em Administração pela Faculdades de Itapiranga, FAI, Brasil.

${ }^{2}$ Bacharel em Administração pela Faculdades de Itapiranga, FAI, Brasil. E-mail: fabiane favretto@hotmail.com

${ }^{3}$ Mestre em Comunicação pela Universidade Federal de Santa Maria, UFSM, Brasil.
} 


\section{INTRODUÇÃO}

O termo e os estudos acerca da publicidade, apesar de serem construídos ainda ao longo do século XX, resultam em grandes e constantes mudanças, tanto na conduta da sociedade como também no comportamento dos consumidores. Neste sentido, trata-se de um termo que não há como findar, pois está em constante desenvolvimento, e provém de uma área que, acima de tudo, todas as empresas necessitam, independentemente do ramo ou de sua situação (Kawano \& Trindade 2007).

A publicidade tem como função primordial tornar público aquilo que é de interesse de todos. Exerce o poder não somente de influenciar uma compra, mas de sugestionar atitudes e comportamentos tidos ou adotados como um padrão a ser seguido pelos consumidores. Portanto, ela atua de forma a favorecer e impulsionar o consumo, através da construção de significados e conceitos para marcas, produtos e serviços (Trindade, 2009).

Partindo destas considerações iniciais, este estudo teve como objetivo realizar um mapeamento bibliométrico sobre os principais estudos acerca do termo publicidade na base de Dados Spell. Neste sentido, buscou-se identificar quais foram os principais autores, instituições e periódicos que publicaram nos últimos anos sobre o tema, analisando as redes de colaborações entres eles.

Quanto à necessidade e à importância de se estudar o tema, percebe-se um mercado em que a competitividade é crescente. Além disso, esse é um tema que está constantemente em mudança e desenvolvimento, pois os consumidores também se transformam e mudam seus hábitos cotidianamente, principalmente, se considerar os avanços da internet e as novas relações que criam na sociedade.

Em resposta a isso, a Revista Exame (2012) destaca que, em relação a investimentos em publicidade, estima-se que, as empresas que dependem de suas ações de marketing para vender, investem aproximadamente $10 \%$ do seu faturamento. E mesmo as empresas que não consideram a publicidade como peças-chave na venda investem de $3 \%$ a $5 \%$ de seu faturamento.

Assim, considerando um mercado que está permanentemente em evolução, as empresas precisam se adaptar e buscar sempre pelas melhores formas de publicidade para a sua marca, seu produto ou serviço, garantindo aumento na receita da empresa e evitando dispêndios desnecessários.

Nesta perspectiva, destaca-se a publicidade relacionada com a difusão das ideias, e um dos meios mais virais para o sucesso desse processo é a internet (Torres, 2009). O comércio online alcança também lugar de destaque nos setores de marketing e comunicação das grandes empresas e agências de publicidade. Não se pode desconsiderar o crescente número de pessoas que usufruem desta ferramenta, quase metade da população Brasileira possui acesso à rede (Santos \& Miranda, 2015). Observa-se que o comércio online cresceu 11\% no ano de $2016 \mathrm{em}$ comparação com 2015, representando um faturamento de R\$ 53,4 bilhões, demonstrando que a crise atinge de forma menos significativa o setor (G1 Notícias, 2017).

Ainda em relação a sua importância de estudo, vale citar que o termo publicidade não é algo tão recente, e durante todo este processo se aproveitou de estereótipos que já eram vigentes na sociedade, pois já havia um entendimento social sobre sua aproximação com marca-público. Contudo, nas últimas décadas, com o crescimento dos movimentos sociais, não se aceita mais algumas práticas estereotipadas que até então circulavam normalmente na sociedade. Por consequência, os estudos de publicidade também se atentaram para o lado social que estava sendo deixado de lado. Assim sendo, buscou-se por fontes que tratam destes assuntos mais 
incipientes, como estereótipos, etnia, raça. Desta maneira, estes estudos tiveram a necessidade de focar em pesquisas mais recentes, que muitas vezes nem estão disseminadas por muitos artigos. Entretanto, é importante argumentar que artigos referentes aos estudos iniciais sobre a publicidade não foram descartados, buscando com isso, um maior desenvolvimento teórico e de entendimento sobre o tema.

Com vistas a melhor responder aos objetivos propostos, este estudo está estruturado em cinco sessões: primeiramente, tem-se a introdução, que apresentou uma abordagem geral sobre o tema que será tratado a seguir. Posteriormente, percebe-se a necessidade de busca por conceitos teóricos que definam a publicidade, a relação publicidade $\mathrm{X}$ cultura e estudos recentes sobre o tema. Na sequência, faz-se uma descrição detalhada dos procedimentos metodológicos. Na quarta seção, são apresentados e analisados os resultados, problematizando objetivos e tema estudado. E, por fim, apontam-se as principais considerações alcançadas com o presente estudo.

\section{FUNDAMENTAÇÃO TEÓRICA}

A partir desta seção, serão apresentados os conceitos que serviram como base para o desenvolvimento do presente estudo. Foram analisados os principais conteúdos teóricos relacionados à publicidade, bem como a relação publicidade $\mathrm{X}$ cultura. Além disso, retomamse os conceitos de diferentes autores, embasados em seus respectivos estudos, e pesquisas realizadas recentemente acerca do tema objeto da pesquisa.

\subsection{PUBLICIDADE}

Publicidade é a divulgação comercial de uma marca, empresa, produto ou serviço, objetivando transmitir informações que buscam aumentar o desejo por um produto através das diferentes mídias e meios de comunicação (Oliveira \& Arantes, 2008).

Para Normanha Filho (2003), o termo refere-se à função mercadológica de criar e transmitir mensagens de caráter comercial para os consumidores. Por isso, a publicidade não pode ser entendida como um sinônimo de marketing, uma vez que esta é um desmembramento do mesmo. Ainda vale destacar que a publicidade é a parte mais visível do marketing, uma vez que é ela quem está ligada e faz a comunicação direta com o público, o que exige uma equipe capacitada e preparada.

Nesta perspectiva, observa-se que é uma poderosa ferramenta na busca da conscientização (e lembrança) das pessoas quanto a empresa, produto ou serviço. Desta forma, surge a importância de os meios de comunicação que gerenciam publicidades e propagandas serem criativos e inovadores, uma vez que seu principal objetivo é aumentar a receita da empresa (Normanha Filho, 2003).

Os autores Costa et al (2006), em seus estudos, salientam que investimentos tidos com a publicidade são de suma importância para qualquer empresa, independentemente de sua situação, posto que ela tem um efeito bastante positivo na integridade da marca. Na mesma linha de raciocínio, é importante que as empresas tenham conhecimento de seu público-alvo e de suas necessidades, para desta forma, concentrarem recursos no meio e momento de divulgação mais eficiente.

Para Gonçalez (2009), a atividade publicitária se caracteriza com a divulgação de informações, buscando convencer os consumidores com argumentos verdadeiros ou não, sobre determinado assunto. Assim sendo, busca divulgar um fato ou uma ideia com objetivos comerciais para despertar o desejo de compra.

A publicidade tem uma grande capacidade de influência sobre os consumidores. Apesar 
de sua importância, ainda é criticada por estimular o capitalismo e valores consumistas, mostrando assim, seus dois lados (Ting, Run \& Thurasamy, 2015). Isto vai ao encontro da necessidade de um comportamento ético por parte dos publicitários, uma vez que estes têm um grande poder de influência em suas mãos, e um comportamento antiético acabaria por infringir o que é certo e moral, como já alertaram Oliveira e Arantes (2008).

Por fim, observa-se que o processo publicitário tem por finalidade difundir uma marca, e que faz isso por meio de diferentes valores, crenças e significados que circulam na sociedade, ou seja, estão presentes nas mais diversas culturas (Camargo Et al, 2011). Assim, o sub-tópico a seguir busca trazer conceitos acerca da relação publicidade e cultura.

\subsection{PUBLICIDADE X CULTURA}

O presente tópico traz conceitos de cultura bem como a sua relação com a publicidade. Inicialmente, destaca-se que a cultura compreende ética e valores acumulados entre membros de uma sociedade (Solomon, 2016). Esta pode ser compreendida como a maneira em que os fenômenos são vistos, interpretados e assimilados. Ela refere-se aos valores e ao modo de vida de um povo. É por meio da cultura que o mundo e as coisas têm significado (Pereira \& Souza, 2012).

Atualmente, tem-se um conceito de cultura de consumo global, que consiste na ideia de que pessoas do mundo inteiro se unem em devoção comum a uma marca, celebridades, atividades, etc. Assim, as pessoas estão cada vez mais compartilhando ideais, mídias e marcas (Solomon, 2016).

Na relação da cultura com a publicidade pode-se mencionar, em concordância com os estudos de Solomon (2016), que os consumidores estão evoluindo de uma cultura em massa, em que a grande maioria tem preferência pelos mesmos produtos, para uma cultura diversa, na qual se tem uma infinidade de opções.

Ainda em consonância a isso, muitas vezes as empresas buscam novos meios de divulgação para seu produto, pois não estão atendendo as expectativas de vendas, mas não raro estas se esquecem de estudar a cultura do povo local para compreender a viabilidade do mesmo. Em alguns casos o problema não está na publicidade e sim no produto (Solomon, 2016).

Neste sentido, o autor acima citado busca exemplificar, reforçando com a questão: quantos tons de batons existem? Quantas estampas de camisas existem? Desta forma, surge a necessidade das empresas identificarem seu público alvo e focar-se na cultura tida por esse público. Esta identificação desta cultura busca, acima de tudo, criar uma lealdade entre o consumidor e a marca/produto.

Para Solomon (2016), e em relação à dinâmica da cultura, defende-se que já não é um processo fácil de entender, e fica ainda mais complexo quando relacionados ao que move os consumidores. Entretanto, ignorar estas sensibilidades culturais pode ter consequências caras para a empresa, pois é este diferencial que os clientes buscam nas empresas.

Neste sentido, e de acordo com Acevedo (2009), os consumidores costumam atribuir gênero aos produtos e serviços. Este conceito forma-se com base no que a própria empresa busca repassar acerca do produto, através de suas formas de publicidade.

Em relação a isso, mencionam-se ainda os estereótipos na publicidade, uma vez que, quando as organizações transmitem em seus anúncios informações que remetem a um único público, o oposto dificilmente terá admiração por ela. Quanto a isso, percebe-se a necessidade de a empresa se adaptar (Solomon, 2016).

Para Salomon (2016), é importante que as organizações levem em consideração em suas atividades de marketing, questões relacionadas às raças e etnias, também relacionadas à cultura. 
Embora algumas pessoas que ainda possuam pré-conceito possam se sentir incomodadas, as menos favorecidas irão se sentir valorizados. Assim sendo, os pertencentes a esse grupo minoritário se sentiram mais acolhidos pela empresa que considerasse os seus desejos de compras nos anúncios.

Além disso, em conformidade com o autor acima mencionado, a aculturação também é um fator que deve ser levado em consideração, uma vez que, devido aos processos de globalização está cada vez mais comum às pessoas mudarem de países, e cabe às agências de publicidade inseri-los nas atividades locais.

Dentro da publicidade, é comum perceber a utilização de apelos sexuais, de medo, usando crianças, estereótipos de gênero, etc., buscando sempre pela maior atenção do público para um produto/serviço. Contudo, questões sociais muitas vezes não são levadas em consideração, e o que deveria ser um meio de promoção da empresa, acaba por prejudicar sua imagem, devido à interpretação dos consumidores (Acevedo et al. 2009).

Em relação à cultura, ainda acabe relacioná-la com a ética, uma vez que esta vai muito além de passar informações verdadeiras, ela refere-se ao comprometimento social e cultural. Em consonância, este dever ético está sobre o poder das agências de publicidade, representado pelos agentes, por serem eles os responsáveis por repassarem estas informações sem infringir a cultura de ninguém (Acevedo, et al. 2009).

Assim sendo, após conhecerem-se os conceitos base que norteiam o assunto, buscou-se por estudos relacionados à publicidade, divulgação da marca, consumidor e culturas, que serão explanados no tópico a seguir.

\subsection{PESQUISAS RECENTES SOBRE O TEMA}

O presente tópico traz pesquisas já publicadas sobre o tema. A escolha destes ocorreu através da leitura de todos os artigos da amostra, e identificando aqueles mais semelhantes com os anseios de estudo, além de optar pelos mais semelhantes com a realidade local e por serem mais recentes no tema; justamente pelo anseio de estudos incipientes.

O estudo realizado por Seta, Mainardes e Silva (2016), que tinha por objetivo "identificar as ações que os profissionais de gestão de agências de publicidade e propaganda percebem serem ações de relacionamento com seus clientes no intuito de retê-los", teve como objeto de estudo 135 gestores de agências de publicidade, escolhidos aleatoriamente e por acessibilidade. A coleta de dados foi realizada através de um questionário. Como principais conclusões deste estudo, nota-se que as agências têm dificuldade de atender às necessidades de seus clientes, e que falhas na comunicação acabam por dificultar o entendimento por parte dos profissionais de marketing (empresa) e as agências de publicidade (p.2).

O estudo de Hahn et al (2016, p.1), "se propôs a descrever as respostas dos consumidores para anúncios reais expostos em duas comunidades de marca no Facebook: uma de marca icônica e a outra de uma marca local". Para o estudo, foram conduzidos dois levantamentos de campo: um com 985 seguidores de uma marca e outro com 233 consumidores de marca local. Como principais resultados, pode-se mencionar que apesar da marca icônica possuir um maior engajamento, percebido pelas curtidas, comentários e compartilhamentos, ela não possui uma avaliação positiva quanto à resposta emocional ao anúncio. Apesar de o anúncio não ter despertado a emoção nos consumidores, ela despertou o desejo de compra e consumo. Quanto à marca local, esta teve um engajamento muito menor, porém o anúncio mostrou-se mais atraente e fascinante, além de ser avaliado como maravilhoso por grande parte das amostras. 
Em relação à cultura, menciona-se os estudos realizados por Solomon (2016), em que este traz em um capítulo de seu livro, um estudo de caso da relação da Disney com a cultura. Segundo ele, quando a Organização iniciou tinha a sua própria cultura, mas com o tempo percebeu que precisava, além disso, fazer com que seus visitantes de sentissem acolhidos com base em sua própria cultura e hábitos. Aplicando estes conceitos em práticas na Disney, eles mudaram o ângulo do portão frontal, pois após consultar um especialista em Feng Shui (ciência chinesa que busca atrair influências boas da natureza), este afirmou que a mudança traria prosperidade. As bilheterias ficam todas perto de cantos e encostadas na parede, para aumentar a prosperidade. A empresa queima insenço ao finalizar cada prédio e escolhe um dia de sorte para a inarguração. Um dos principais salões de baile tem 888 metros quadrados, pois os chineses consideram oito o número da sorte. Além disso, como os chineses consideram o número quatro como um número de azar, nenhum elevador possui este número para o andar.

Com base nisso, a Disney considera que cada região/país possui sua própria cultura, e a melhor maneira de tornar os momentos dos clientes na Disney inesquecíveis é buscando traços em que todos possam se identificar e se sentirem bem acolhidos.

Após, findada esta parte, já possui-se um conhecimento significante para perceber a importância deste estudo com base em outros já realizados. Assim sendo, o tópico a seguir buscará explanar a metodologia utilizada para esta pesquisa e, posteriormente, seus resultados.

\section{PROCEDIMENTOS METODOLÓGICOS}

A presente pesquisa, de natureza teórico-empírica, caracteriza-se como um estudo descritivo e exploratório. Descritivo, pois apresenta indicador referente às publicações científicas acerca da publicidade, com vistas a um mapeamento da área. Para Gil (2009), pesquisas descritivas buscam descrever as características de alguma população ou fenômeno determinado. Além disso, é exploratório por relacionar a publicidade com o contexto atual, através de uma pesquisa bibliográfica, iniciando um levantamento, estado da arte, sobre a área estudada. Uma pesquisa exploratória busca criar uma maior familiaridade com o problema, buscando torná-lo mais explícito (Gil, 2009).

A presente pesquisa, apesar de analisar números, não faz uma análise aprofundada estatisticamente, característica da pesquisa quantitativa. Assim sendo, este estudo caracterizase como qualitativo, pois busca analisar relações e redes de cooperações entre autores, Instituições de Ensino Superior e Periódicos. Lakatos e Marconi (2010) destacam que a pesquisa qualitativa exige que seja realizada uma coleta de dados para elaborar uma teoria de base, ou seja, o conjunto de conceitos, significados e princípios.

Para alcançar o objetivo do estudo, realizou-se uma pesquisa bibliométrica e uma análise do conteúdo disposto. A pesquisa bibliométrica tem por base materiais já elaborados; principalmente, livros e artigos, buscando analisar e construir indicadores de evolução de um tema (Lakatos \& Marconi, 2010). Com base nisso, a presente pesquisa utilizou-se apenas de artigos para os estudos.

Buscando por um maior conhecimento sobre o tema publicidade, realizou-se uma revisão sistemática na base de dados do Site Spell somente no mês de Março de 2017. Inicialmente, é importante enfatizar que nenhum corte transversal (cross sectional) foi realizado, uma vez que, nenhum filtro de tempo, por exemplo, foi inserido. Justifica-se não ser necessário pelo fato de buscar-se por uma abordagem geral e ampla sobre o tema, e que efetivamente dê conta de mapear os estudos da área no campo da Administração. Acredita-se que desta forma, esta fase do estudo proporciona maior imersão do pesquisador no tema 
estudado, favorecendo assim para uma qualidade melhor na pesquisa.

A palavra-chave inserida na busca foi Publicidade. Como filtros definiu-se que seria necessário que o termo tivesse presente no resumo, além disso, buscou-se por artigos do campo da Administração. Não se optou por filtros referentes a idiomas, justamente por ser uma abordagem geral. Assim sendo, como objeto de estudo foram classificados 61 artigos científicos, da área da Administração, que tinham em seu resumo o termo publicidade. utilizados:

A seguir será apresentado o Quadro 1, que descreve as etapas da pesquisa e os filtros

\section{Quadro 01: Etapas da pesquisa e filtros utilizados}

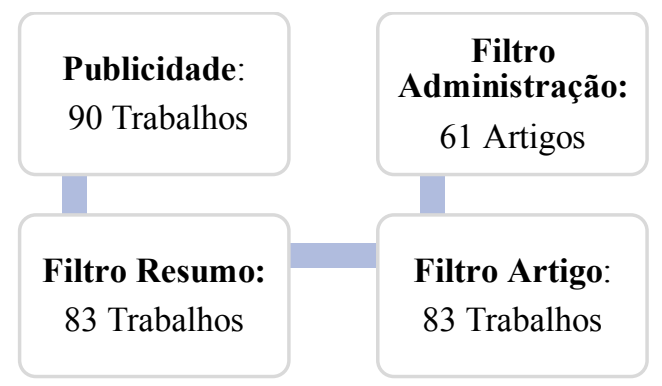

Fonte: Dados da pesquisa.

Após a classificação dos 61 artigos, iniciou-se o levantamento de dados e informações contidas em cada uma deles. E a partir dessas informações coletadas, foi possível realizar uma interpretação e análise qualitativa dos resultados.

Quanto à tabulação dos resultados, que será detalhado no Quadro 02, esta ocorreu através do Excel. Com base nisso, foi possível identificar as categorias de principais autores, Instituições de Ensino Superiores (IES) e periódicos que mais publicaram constructos relacionados, indicações de futuras pesquisas, etc.

Já em relação à análise, ela foi realizada por meio da análise de conteúdo, e é de suma importância citar que todas as conclusões tiveram como base apenas as informações dispostas nos artigos e na Base Spell, assim sendo, se esta análise utilizasse outras plataformas, possivelmente os resultados se alterariam.

O quadro descreve o processo de análise dos Dados:

Quadro 02: Etapas do processo de análise dos resultados

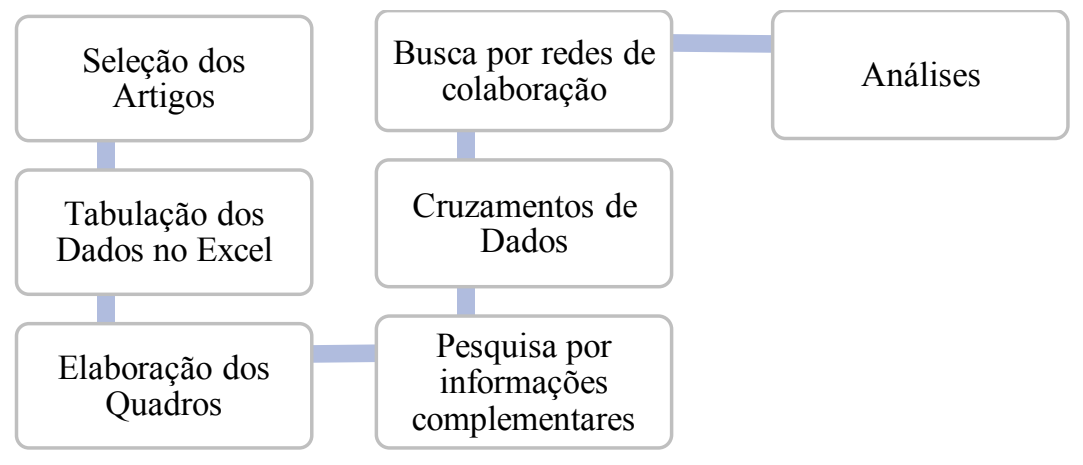

Fonte: Dados da Pesquisa.

Desta forma, após detalhado todo o processo metodológico e a forma de análise, cabe no tópico a seguir, fazer uma descrição das análises obtidas com o nosso estudo. 


\section{DESCRIÇÃO E ANÁLISE DOS RESULTADOS}

Com base nas análises das publicações, que teve como objeto de pesquisa 61 artigos classificados, houve a possibilidade de realizar um mapeamento dos dados, que serão posteriormente apresentados através de descrições, tabelas e gráficos.

Inicialmente, a Tabela 1 demonstrará os autores destaque no tema:

Tabela 01: principais autores

\begin{tabular}{l|c}
\hline \multicolumn{1}{c|}{ AUTOR } & QUANTIDADE DE PUBLICAÇÕES \\
\hline Eneus Trindade & 4 \\
\hline André Luiz Maranhão de Souza Leão & 3 \\
\hline Ildembergue Leite de Souza & 3 \\
\hline Jouliana Jordan Nohara & 2 \\
\hline Demais autores com 1 publicação & 126 \\
\hline Total & $\mathbf{1 3 8}$ \\
\hline
\end{tabular}

Fonte: Dados da pesquisa.

Na Tabela 01, pode-se enfatizar que o autor Eneus Trindade foi quem mais publicou acerca do tema publicidade, apesar de ter apenas 04 publicações. Em relação a elas, destaca-se que dois artigos dele foram feitos com a mesma linha de pesquisa, porém um foi desdobramento de outro. Inicialmente, observa-se que esse fato pode até não gerar novos resultados de pesquisa para o tema estudado. Porém, contribui de forma significativa para esta pesquisa, pois revela a preocupação e interesse do autor em publicar sobre publicidade, buscando a problematização de seus próprios pensamentos e análises.

Eneus Trindade é docente da disciplina de Teoria e Técnica de Publicidade, no curso de Publicidade e Propaganda da PUC/SP. Além disso, Trindade é Vice-líder do grupo de estudos em semiótica comunicação, cultura e consumo e membro do grupo de pesquisa coletivo de estudos em estética, ambos pela PUC/SP, justificando assim sua participação como o autor que mais publicou.

Na segunda posição, como autores que mais publicaram estão André Leão e Ilderbergue Souza, ambos com 03 publicações cada um. Esta igualdade deve-se ao fato de que Leão e Souza publicaram juntos 02 artigos, formando assim uma rede de cooperação. Esta pode justificar-se pelo fato destes atuarem na mesma Instituição, a Universidade Federal de Pernambuco (UFPE). Assim sendo, além destes dois artigos publicados em conjunto, ambos publicaram mais uma vez. André Leão é formado no Curso de Comunicação Social/ Publicidade e Propaganda e é Doutor em Administração, pela UFPE. Atualmente, é professor de graduação e pós-graduação pela UFPE, e seu foco de pesquisa atual é a indústria do entretenimento. Ildelbergue Souza é graduado, pós-graduado, Mestre e Doutor pela UFPE. Atualmente, é professor de graduação e pós-graduação pela UFPE, e seu foco de pesquisa é cultura de consumo, branding e publicidade.

Jouliana Nohara foi a autora que publicou duas vezes. Nohara é Graduada, Mestre e Doutora pela Fundação Getúlio Vargas/ SP. Atualmente, ela é professora no centro universitário das faculdades metropolitanas unidas/FMU.

Ainda em relação aos autores, é importante defender que não foi necessário fazer uma análise entre autores que publicam juntos, uma vez que, foi possível listar todos os que publicaram mais que uma vez acerca do tema. Assim sendo, observou-se que a única rede de cooperação identificada em nossa base de dados ocorreu entre os autores Leão e Souza, pois possivelmente se outros autores publicassem em conjunto sobre o assunto, estariam elencados na Tabela. 
A seguir, a Tabela 2 apresentará o modelo metodológico utilizado nos artigos base de estudo. Observa-se as formas de pesquisa, caracterizando-se como Pesquisa Qualitativa, Quantitativa e Revisão teórica.

Tabela 02: abordagem metodológica dos artigos

\begin{tabular}{l|l|l}
\hline Abordagem & Quant. De Publicações & \% \\
\hline Artigos Qualitativos & 29 & 47,5 \\
\hline Artigos Revisão Bibliográfica & 17 & 27,9 \\
\hline Artigos Quantitativos & 13 & 21,3 \\
\hline Artigos Qualitativo-quantitativos & 02 & 3,3 \\
\hline Total & $\mathbf{6 1}$ & $\mathbf{1 0 0}$ \\
\hline
\end{tabular}

Fonte: Dados da pesquisa.

Verifica-se, com base na Tabela 02 , que a grande maioria dos artigos $(47,5 \%)$ caracterizam-se como qualitativos, sendo que as estratégias de pesquisa utilizadas em 11 destes 29 artigos foi o estudo de caso e em outros 08, entrevistas. Os demais se referem a grupos focais, análise semiótica, formulário, etc. $\mathrm{O}$ segundo método de pesquisa mais utilizado foi à revisão bibliográfica com uma representatividade de 27,9\%. Por fim, 21,3\% dos artigos caracterizam-se como quantitativos, e 3,3\% com duplo método, quantitativo e qualitativo. No método quantitativo, a estratégia de pesquisa mais utilizada foi o questionário (survey), explorado em 08 pesquisas. Os demais, quantitativos, usaram de dados secundários, ex post facto, etc.

Em relação aos métodos empregados, destaca-se que todos eles possuem seus prós e contras. Quanto ao método qualitativo, reporta-se que nos últimos anos este teve um crescimento considerável, possivelmente, porque os pesquisadores estão cada vez mais buscando por informações aprofundadas para entender processos de forma mais detalhada, e não estatísticos. Assim sendo, ficou perceptível este crescimento na busca, entretanto os estudos desta metodologia acabam por ter uma análise mais subjetiva e interpretativa, e podem ter maior influência de interpretação do pesquisador. Além disso, vale destacar que muitas vezes os próprios autores criam o modelo de pesquisa, mas acabam por não mencioná-lo, não informar se houve validação do mesmo, e nem disponibilizar este para os leitores interessados, o que dificulta o seu desenvolvimento e comprovação de sua veracidade, como observado na coleta de dados.

Em consonância, vale especificar que dos 61 artigos base do estudo, apenas 01 disponibilizava como anexo o instrumento de coleta de dados, e este se referia a um estudo quantitativo. Neste sentido, observa-se que quando não é disponibilizado o instrumento de coleta de dados em anexo, tem-se um fator limitante para futuros estudos, pelo fato dos pesquisadores não terem informações suficientes para que a pesquisa possa ser reaplicada, na busca por uma comparação ou comprovação de veracidade.

Quanto a outros autores utilizados como base para as pesquisas, é importante mencionar que 17 destes artigos não tinham a necessidade de autor modelo por ser apenas uma revisão teórica. Dos outros 44 artigos, apenas em 16 estes autores foram mencionados. Ainda em relação a isso, apenas 01 autor modelo foi mencionado duas vezes, sendo que este se referia aos estudos de Eneus Trindade, aquele mesmo estudo que já se mencionou ser um desdobramento.

Quanto às Instituições de Ensino que mais obtiveram destaque, vale informar que a sua identificação deu-se pela probabilidade de participação atual, ou até mesmo, a igualdade de IES dos autores do artigo. Tais informações serão mencionadas na Tabela a seguir. 
Tabela 03: Principais Instituições de Ensino

\begin{tabular}{l|l|l}
\hline INSTITUIÇÕES DE ENSINO & $\begin{array}{l}\text { QUANTIDADE } \\
\text { PUBLICAÇÕES }\end{array}$ & DE \\
\hline Universidade de São Paulo - USP & 10 & 12,82 \\
\hline Universidade Católica de São Paulo - PUC/SP & 6 & 7,69 \\
\hline Universidade Federal do Rio de Janeiro - UFRJ & 4 & 5,13 \\
\hline Universidade Católica do Rio de Janeiro - PUC/RJ & 4 & 5,13 \\
\hline Escola Superior de Propaganda e Marketing - ESPM & 3 & 3,85 \\
\hline Universidade Federal de Santa Maria - UFSM & 3 & 3,85 \\
\hline Outras Instituições (2) & 10 & 12,82 \\
\hline Outras Instituições (1) & 38 & 48,71 \\
\hline Total & $\mathbf{7 8}$ & $\mathbf{1 0 0}$ \\
\hline
\end{tabular}

Fonte: Dados da pesquisa.

Ao reportar-se sobre as Principais Instituições de Ensino Superior, em relação à Tabela 03, destaca-se que a Universidade de São Paulo - USP foi a que mais publicou acerca do tema. Como possível justificativa tem-se o fato de a USP possuir o curso de Publicidade e Propaganda, além de outros cursos que têm em sua grade curricular disciplinas que remetem ao tema, como por exemplo, o curso de Administração, Jornalismo, Educomunicação, etc.

A Universidade Católica de São Paulo - PUC/SP obteve 06 publicações, ficando no $2^{\circ}$ lugar de Instituições que mais publicam. A presente Instituição, bem como a anterior, possui o curso de Publicidade e Propaganda, além de outros cursos que contenham em sua grade curricular disciplinas que se relacionam com o tema, como Jornalismo, Administração, etc.

A Terceira Instituição que mais publicou foi a Universidade Federal do Rio de JaneiroUFRJ, com 04 publicações, e que não possui o curso de Publicidade e Propaganda. Contudo, possui cursos com disciplinas similares em sua grade, como Administração, Jornalismo, etc. Com o mesmo número de publicações tem-se a Universidade Católica do Rio de Janeiro PUC/RJ. Já a Escola Superior de Propaganda e Marketing - ESPM e a Universidade Federal de Santa Maria - UFSM, ambas possuem 03 publicações acerca do tema, além de apresentarem o curso de Publicidade e Propaganda, que justifica as publicações sobre o tema.

Nesta perspectiva, vale destacar que o número de resultados de artigos relacionados à publicidade é relativamente pequeno pelo fato de que, teoricamente, todas as IES que possuem o curso de Publicidade e Propaganda têm inclinação a publicar mais sobre o tema. Assim sendo, possivelmente, se não tivesse sido inserido na busca o filtro Administração, a tendência é que o número de artigos seria maior, e consequentemente, a Instituições que possuem o curso de Publicidade e Propaganda, teriam um maior destaque.

A seguir, a Tabela 4 busca trazer os principais periódicos que publicam acerca da publicidade.

Tabela 04: Principais Periódicos

\begin{tabular}{l|c|c}
\hline \multicolumn{1}{c|}{ NOME DOS PERIÓDICOS } & $\begin{array}{l}\text { QUANTIDADE } \\
\text { PUBLICAÇÕES }\end{array}$ & DE \\
\hline Pensamento e Realidade & 9 & 14,8 \\
\hline Revista Brasileira de Marketing & 6 & 9,8 \\
\hline Revista de Administração Contemporânea & 4 & 6,6 \\
\hline Revista Administração em Diálogo & 3 & 4,9 \\
\hline Demais periódicos com 2 publicações & 16 & 26,2 \\
\hline Demais revistas com 1 publicação & 23 & 37,7 \\
\hline Total & $\mathbf{6 1}$ & $\mathbf{1 0 0}$ \\
\hline
\end{tabular}

Fonte: Dados da pesquisa.

Em relação à Tabela 04, destaca-se que a revista Pensamento e Realidade foi quem mais 
publicou acerca do tema, com uma representatividade de 14,8\%. Uma possibilidade de justificativa é porque se percebe que a revista publica trabalhos sobre a realidade brasileira e internacional, considerando reflexões acerca das ciências humanas e ciências sociais aplicadas. Além disso, a revista adota uma posição pluralista de ideias.

A segunda revista que mais publicou foi a Revista Brasileira de Marketing, com 9,8\%. Esta revista busca divulgar a produção científica brasileira na área do marketing, que está relacionada com o tema de pesquisa.

Posteriormente, tem-se a Revista de Administração Contemporânea e a Revista Administração em Diálogo (RAD), com 04 e 03 publicações, respectivamente. A primeira tem como missão colaborar para o entendimento da Administração e das Ciências Contábeis através da divulgação de pesquisas, análises teóricas, documento, etc. Já a RAD tem como objetivo disponibilizar conhecimento e trocar experiências e resultados de pesquisa, entre especialistas e pesquisadores da PUC-SP e de outras instituições envolvidas.

Assim sendo, justifica-se que a RAD possui um destaque justamente por ser a revista de uma IES, o que a impulsiona. Além disso, neste momento ocorre uma aproximação, pois a Instituição e a Revista buscam contribuir umas com as outras. Em consonância, a presente revista acaba por ter um diferencial em relação as demais, justamente por estas contarem apenas com um escopo referente a área, mas não possuem nenhuma Instituição de Ensino Superior como alicerce.

Em relação ao ano de publicação, o Gráfico a seguir buscará fazer esta comparação.

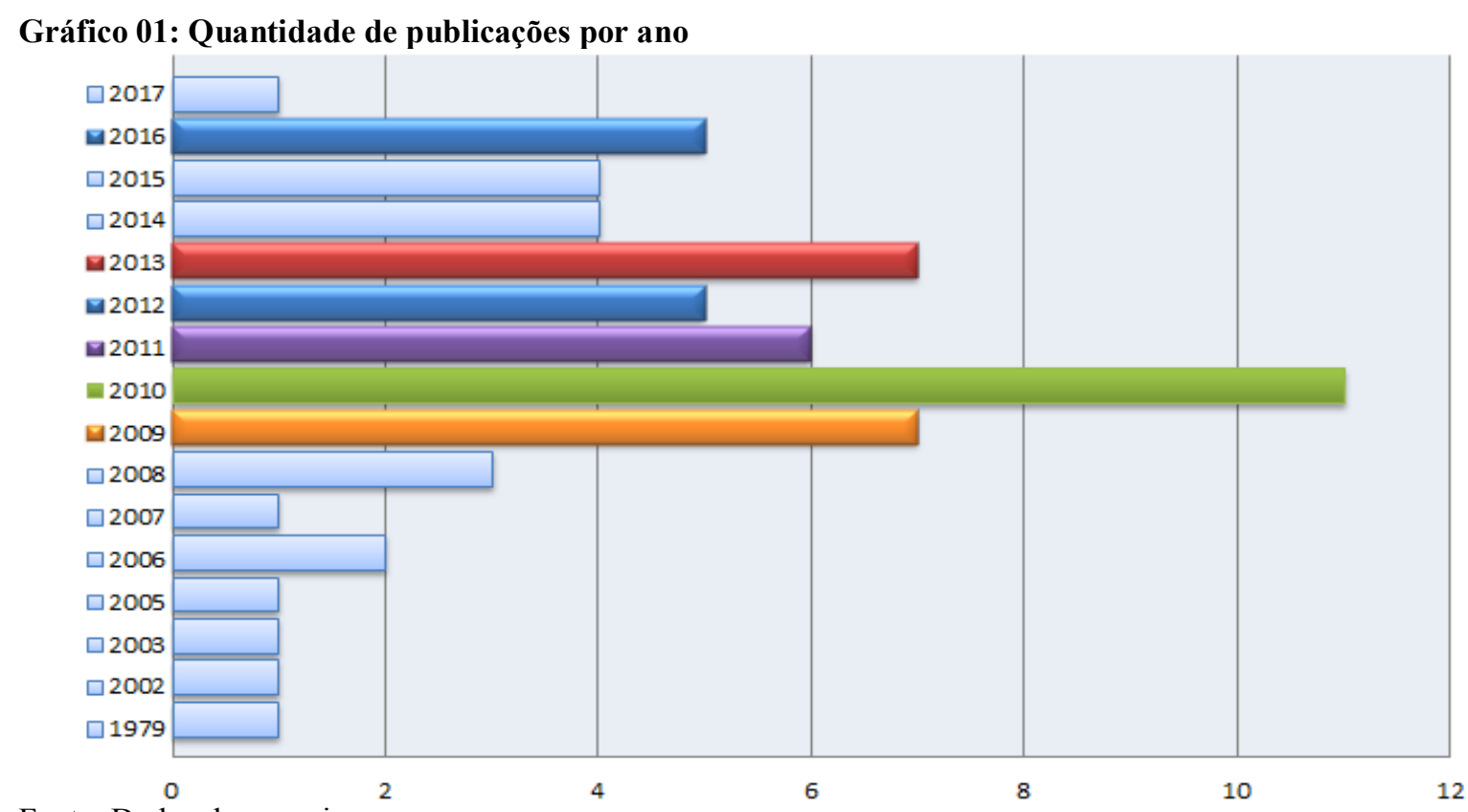

Fonte: Dados da pesquisa.

Em relação aos anos de publicações dos artigos objeto deste estudo, percebe-se que o ano de 2010 foi o momento em que mais se obteve publicações, correspondendo a 11 do total. Em seguida, tem-se o ano de 2009 e 2013, ambos com 07 publicações. Na sequência, observamse os anos de 2011, 2013 e 2016, com 06, 05 e 05 publicações, respectivamente.

Em relação a isso, é possível defender que, como a busca ocorreu em uma base de dados referente a periódicos, o estudo possivelmente tenha sido desenvolvido pelo autor pelo menos um ano antes, uma vez que o processo de aprovação para uma revista demora um tempo considerável. Assim, os estudos publicados em 2010, possivelmente, tiveram base em 
acontecimentos de 2008, que vai ao encontro dos estudos realizados por Golçalez (2009), que diz que aquele foi um período em que novas áreas e profissões relacionadas à publicidade e propaganda foram surgindo, uma vez que, naquele período, os estudantes que saíam das universidades estavam ocupando cargos que nem existiam no momento em que ingressaram nas mesmas.

Em conformidade a isso, é importante salientar que apesar de que na busca deu-se prioridade por artigos mais incipientes sobre o tema, justamente para entender o que move a publicidade no momento, conceitos menos atuais não podem ser deixados de lado, pois estes têm a capacidade de dar suporte para a construção de um referencial teórico, surgindo assim, a importância de entendimento dos primeiros artigos publicados sobre o tema, que neste caso ocorreu no ano de 1979.

Prosseguindo, surge a importância de mencionar os constructos base dos artigos da amostra, que serão apresentados na tabela a seguir.

Tabela 05: Principais constructos

\begin{tabular}{|c|c|c|}
\hline CONSTRUTOS & $\begin{array}{l}\text { QUANTIDADE } \\
\text { UTILIZAÇÃO }\end{array}$ & $\%$ \\
\hline Marketing & 14 & 8,14 \\
\hline Marca & 10 & 5,81 \\
\hline Propaganda & 08 & 4,65 \\
\hline Consumidor & 08 & 4,65 \\
\hline Ética & 04 & 2,33 \\
\hline Cultura & 03 & 1,74 \\
\hline Publicitários & 03 & 1,74 \\
\hline Demais constructos & 122 & 70,94 \\
\hline Total & 172 & 100 \\
\hline
\end{tabular}

Fonte: Dados da pesquisa.

Em relação aos constructos, como percebido na Tabela 05, marketing é o termo que mais se destacou em comparação aos demais, com (6,8\%). Uma possibilidade de explicação seria pelo fato de esta ser a grande área que envolve a publicidade e sempre que se fala de um está se mencionando o outro. Marca foi o constructo que apareceu 10 vezes (4,85\%), uma vez que, toda publicidade é feita para uma marca, produto ou serviço, que vai ao encontro das considerações de Torres (2009).

$\mathrm{O}$ termo propaganda apareceu em $3^{\circ}$ colocação sendo mencionado 08 vezes. Neste sentido, argumenta-se que, em consonância com os estudos de Gonçalez (2009), muitas pessoas ainda têm o falso conceito de que publicidade e propaganda são a mesma coisa, ou sinônimos, entretanto apesar destes terem significados diferentes, pode esse ter sido o motivo de ambos aparecerem com tanta frequência na pesquisa.

Em seguida, com o mesmo percentual de citações, tem-se o termo consumidor. Uma possibilidade de justificativa é de que quando levado em consideração os conceitos de Normanha Filho (2003), em que todas as ações de marketing, publicidade e propaganda surgem para difundir o conhecimento acerca de uma marca para atrair e manter consumidores.

Em seguida, têm-se os termos: ética, com 04 publicações e os termos cultura e publicitários com 03 publicações cada um, respectivamente. Quanto a isso, vale destacar que os três termos se relacionam uma vez que, os publicitários detêm a responsabilidade de transmitir informações de forma ética e respeitando a cultura de todos os atingidos nesta cadeia de divulgação, conforme já defendido nos estudos de Oliveira e Arantes (2008).

Por fim, é importante trazer quais as indicações de futuros estudos, com base no que 
mencionado nos artigos base deste estudo. Estas informações estão dispostas no Quadro a seguir:

Quadro 03: Indicaçães de futuros estudos
\begin{tabular}{|l|l|}
\hline INDICAÇÃO DE ESTUDO & AUTOR (ANO) \\
\hline $\begin{array}{l}\text { Investigar as sinergias entre outras ações de comunicação e apurar seu impacto no } \\
\text { desempenho comportamental na rede social. }\end{array}$ & $\begin{array}{l}\text { Porto, Mendonça \& } \\
\text { Milan (2016) }\end{array}$ \\
\hline $\begin{array}{l}\text { Aprofundar o conhecimento sobre as consequências de diferentes tipos de } \\
\text { campanhas de marketing em meios de comunicação social }\end{array}$ & Hahn et al (2016) \\
\hline $\begin{array}{l}\text { Analisar se os profissionais de agência de publicidade entendem o significado de MR } \\
\text { (marketing de rede) e como este acontece dentro das agências. }\end{array}$ & $\begin{array}{l}\text { Seta, Mainardes \& \& } \\
\text { Silva (2016) }\end{array}$ \\
\hline $\begin{array}{l}\text { Investigar a relação entre a gestão do conhecimento, o uso da TI e inovação, tanto } \\
\text { nas agências de publicidade quanto em outras empresas do setor de serviços. }\end{array}$ & $\begin{array}{l}\text { Ferraz, Sila \& Sales } \\
\text { (2015) }\end{array}$ \\
\hline $\begin{array}{l}\text { Verificar qual o conteúdo mais eficaz na argumentação de anúncios publicitários, } \\
\text { para cada categoria de produto: racional ou emocional. }\end{array}$ & $\begin{array}{l}\text { Marin, Pizzinatto \& } \\
\text { giuliane (2014) }\end{array}$ \\
\hline $\begin{array}{l}\text { Ver a aplicabilidade de questões culturais, segmentação de classes criativas ou a a } \\
\text { formação de clusters criativos para a exportação. }\end{array}$ & $\begin{array}{l}\text { Bianchi1 \& Borini } \\
\text { (2013) }\end{array}$ \\
\hline $\begin{array}{l}\text { Estudar quem é responsável por exigir comportamentos éticos na publicidade: os } \\
\text { agentes publicitários ou a sociedade }\end{array}$ & Acevedo et al (2009) \\
\hline $\begin{array}{l}\text { Analisar a construção de alguma outra marca similar já estudada (rede de } \\
\text { supermercados), buscando por comparação, sob o enfoque cultural. }\end{array}$ & Camargo et al (2011) \\
\hline $\begin{array}{l}\text { Ver qual a percepção das empresas participantes do ISE (Índice de sustentabilidade } \\
\text { Empresarial), referente a sua importância. }\end{array}$ & $\begin{array}{l}\text { Figueiredo, Abreu \& } \\
\text { Las Casas (2009) }\end{array}$ \\
\hline $\begin{array}{l}\text { Analisar a percepção de gestores e empresários que investem outdoors na } \\
\text { perspectiva de aumentarem a visibilidade deles e alavancar vendas. }\end{array}$ & $\begin{array}{l}\text { Lopes, Lemos \& } \\
\text { Pinheiro (2009) }\end{array}$ \\
\hline
\end{tabular}

Fonte: Dados da pesquisa.

Em relação ao Quadro 03, referente às indicações de futuros estudos, é importante destacar que os autores, no geral, indicam pesquisas que possam trazer informações mais minuciosas acerca de todo o processo de marketing, desde a escolha por mercados até a efetivação da venda. Percebe-se que ainda há muito a ser analisado em relação aos meios de divulgação, uma vez que, as diversidades de ferramentas permitem que as empresas em ação conjunta com as agências de publicidade, possam usufruir a melhor maneira, em consonância com o seu mercado.

Como destacado pelos autores, o comportamento do consumidor e dos agentes de publicidade também são fatores que devem ser estudados, afinal, são eles que representarão esta cadeia.

Por fim, após diversos dados e informações nesta etapa de apresentação dos resultados e de análises, o tópico a seguir, traz as principais considerações pontuadas pelos pesquisadores neste estudo.

\section{CONSIDERAÇÕES FINAIS}

Após a realização das análises, a presente seção trará as conclusões do estudo. Inicialmente é importante salientar que o objetivo inicial do estudo, realizar um mapeamento bibliométrico sobre os principais estudos acerca do termo publicidade na base de dados Spell, foi alcançado, através de uma pesquisa qualitativa, descritiva e exploratória, utilizando-se da análise de conteúdo para interpretar os resultados.

Com base nisso, pode-se concluir, inicialmente, que em relação aos autores nenhum teve um destaque assíduo, pois aquele que mais se destacou teve apenas 04 publicações. Enquanto isso, outros 126 autores publicaram 01 artigo, o que significa que o tema está muito bem difundido e muito autores buscam expandir seus conhecimentos acerca do mesmo. Como 
justificativa, pode-se ressaltar que a publicidade é um tema que se mantém atual, afinal é algo essencial em todo momento, os de crise inclusive e principalmente. Além disso, trata-se de uma área que está a todo tempo em desenvolvimento e evolução, pois acompanha de forma simultânea os desdobramentos da tecnologia.

Quanto ao método de pesquisa, é necessário argumentar que todos eles (quantitativos, qualitativos e revisão teórica) tiverem números significantes, o que se avalia como importante, uma vez que diferentes percepções são obtidas sobre o tema quando são realizadas novas análises com diferentes métodos.

Em relação a isso, nas indicações de estudos mencionadas pelos autores dos artigos da amostra, estes indicam que, para estudos realizados com métodos quantitativos, sugere-se uma análise mais aprofundada utilizando o método qualitativo.

Quanto ao instrumento de coleta de dados, apenas um artigo disponibilizava este no anexo. Assim sendo, para a maioria das pesquisas, se outros pesquisadores tiverem interesse em ampliar o estudo ou comprovar sua veracidade, possivelmente não terão informações suficientes para que isso ocorra. Quanto a isso, acredita-se que uma justificativa para que os autores acabam por não disponibilizar o instrumento em anexo pelo enxuto tamanho de um artigo e por isso não ser uma exigência da maioria das revistas.

Em consonância com as principais Instituições de Ensino Superior, menciona-se que com exceção da UFSM, as demais IES estão todas situadas na região Sudeste, o que pode se justifica por esta região ser a que possui maior capital econômico, grandes agências de publicidade e as principais empresas de comunicação. Nesta perspectiva, a pesquisa em publicidade também possui um campo maior.

Quanto à ligação entre principais autores e principais IES, detalha-se que apenas TRINDADE, leva consigo para o topo do ranking de publicações a sua IES (PUC/SP). Os demais não têm suas IES na lista das principais Instituições. O fato de as IES dos autores não estarem na lista pode ser pela hipótese destes ainda não estarem trabalhando na Instituição no período da pesquisa. Outra possibilidade é a de os autores não levarem consigo no artigo o nome da Instituição, por questões próprias, e que acaba por se perder uma conexão.

Em relação aos Periódicos que mais publicam sobre o tema, argumenta-se que todos possuem como objetivo a publicação de assuntos contemporâneos, nas áreas que se relacionam à pesquisa, o que as torna referência para docentes, discentes e profissionais da área. Ainda em relação às Revistas, é importante ressaltar que além das em destaque, outras 33 organizações publicam sobre o tema, com base na amostra, o que é um dado importante, uma vez que, a difusão do tema está satisfatória.

$\mathrm{O}$ fato da PUC/SP estar entre as IES que mais publicam e a RAD estar também neste ranking se justifica pelo fato dela ser uma revista do Programa de estudo de Pós-graduação da Instituição acima. Diante disso, é importante salientar que, as Instituições que possuem suas próprias revistas e as utilizam de forma eficaz, acabam por participar de uma rede de colaboração, onde a Instituição de Ensino ajuda na promoção da Revista e vice-versa.

Em relação aos anos de publicação, o pico de publicações pode estar relacionado com o aumento de mercado, campos e áreas da publicidade. Assim, quanto mais pessoas trabalhando com isso, mais pesquisas acerca do tema, consequentemente.

Em relação aos constructos, é possível concluir que, todos os mencionados acabam se interligando, uma vez que um termo é desdobramento de outro, ou surge em função de outro e assim por diante. Desta forma, falar de publicidade sem remeter-se aos constructos mencionados é quase impraticável.

Como limitação do estudo, destaca-se a utilização de uma única Base de Dados para análise, tendo assim um gargalo de informações. Além disso, por ter como base apenas artigos, percebe-se que os estudos publicados neste meio são menos incipientes, necessitando assim, principalmente para a conceituação do tema, a busca por outras pesquisas, publicadas em e-books, por exemplo, justamente por tratarem 
destes assuntos mais contemporâneos.

Como indicação de futuros estudos tem-se ampliar a Base de Dados, pois assim outros fatores poderiam ser identificados, como por exemplo, as redes de cooperação, que há uma possibilidade de existirem dentro do tema, porém, nem sempre será perceptível utilizando só uma base.

Outra indicação de futuros estudos seria a análise da utilização dos diferentes perfis, apelos sexuais e estereótipos nos anúncios de publicidade, buscando assim pela identificação de sua interferência com a cultura.

\section{REFERÊNCIAS}

Acevedo, Nohara, J., Ampanário, A. \& Telles, C. C. P. (2009). Ética da propaganda sob o olhar dos publicitários. RAE-eletrônica, 8(1), 1-26.

Camargo, M., Toaldo, M.; Mady, B. \& Akel Sobrinho, Z. (2011). Cultura da marca: estratégia ou acaso? Revista Ciências Administrativas, 17(3), 946-972.

Costa, L., Matias, M. J., Pargana, M., Penela, N. \& Reis, A. R. (2006). A relação entre satisfação do consumidor, despesa em publicidade e lealdade do consumidor à marca: um estudo no setor de fast-food em Portugal. Revista de Administração FACES Journal, 5(2), 41-51.

E-commerce cresce 11\% em 2016; vendas do Natal sobem 3,8\%. JANEIRO, 2017. Disponível Em: http://g1.globo.com/economia/seu-dinheiro/noticia/e-commerce-cresce-11-em-2016-vendas-donatal-sobem-38.ghtml. Acesso em: 21/04/2017.

Gil, A.C. (2009) Como elaborar projetos de pesquisa. Edição: 4ªd. Sao Paulo: Atlas S.A., 2009

Gonçalez, M.C. (2009). Publicidade e propaganda. Curitiba, Disponível em: https://books.google.com.br/books?id=mcjMntKor5gC\&pg=PA17\&lpg=PA17\&dq=aco $\underline{\text { ntecimentos }}+$ que + envolvem + publicidade $+e m+2008 \&$ source $=$ bl \&ots $=9$ XgmwrdGZ7\&s ig=fI-ORgU5RjECB-zk1YhqkOs1TZg\&hl=pt-

BR\&sa $=$ X\&ved=0ahUKEwjsjvuEoc TAhXMg5AKHRh0CKsQ6AEIVzAI\#v=onepage \&q $=$ acontecimentos $\% 20$ que $\% 20$ envolvem $\% 20$ publicidade $\% 20 \mathrm{em} \% 202008 \& \mathrm{f}=$ false. Acesso em: 01/05/2017.

Hahn, I. S.; Scherer, F. L.; Oliveira, M. C. S. F. \& Scheid, R. (2016). Resposta Emocional à Publicidade em Mídias Sociais. Revista Pensamento Contemporâneo em Administração, 10(1), 140-151.

Kawano, D. R. \& Trindade, E. (2007). A publicidade contemporânea e as teorias da comunicação de massa. Revista Brasileira de Marketing, 6(2), 165-174.

Lakatos, E.M. \& Marconi, A.A. (2008). Metodologia científica. 5 ed. 2 reimpr. São Paulo: Atlas.

Normanha Filho, M. A. (2003). Marketing, Propaganda e Publicidade - um estudo dos termos no Brasil. Revista Ibero-Americana de Estratégia, 2(1), 33-42.

Oliveira, R. S. \& Arantes, M. M. (2008). A publicidade enganosa sob o ponto de vista da ética no marketing - uma reflexão sobre as casas Bahia. Revista Administração em Diálogo, 10(1), 1-17, 2008.

Pereira, S.J.N., \&; Souza, E. M. 2012. Azul para os Meninos, Rosa para as Meninas: Heterossexismo, Consumo e Gênero. In: V Encontro de Marketing da Anpad, 2012. Anais... Curitiba- PR2012.

Santos, A. S. D. \& Miranda, G. J. (2015). E-commerce no Brasil: se o segmento é promissor, por que empresas atuantes estão no vermelho? Revista Evidenciação Contábil \& Finanças, 3(1), 54-68.

Seta, R. C.; Mainardes, E. W. \& Silva, R. T. (2016). Ações de Marketing de Relacionamento Utilizadas pelas Agências de Publicidade e Propaganda. Revista Brasileira de 
Marketing, v. 15, n. 2, p. 281-296.

Solomon, M. (2016). O comportamento do consumidor. São Paulo: Bookman. Disponível em: https://books.google.com.br/books?hl=pt-BR\&lr=lang_pt\&id=n1zCwAAQBAJ\&oi $=$ fnd\&pg $=$ PR1\&dq $=$ cultura $+\mathrm{E}+\mathrm{CONSUMIDORES \& ots}=\mathrm{JUcM} 7 \mathrm{wL}$ u5L\&sig=ZH7ZUmyXYaAXQjvbC6bsrnSpXGA\#v=onepage\&q\&f=false. Acesso em: 01/05/2017.

Ting, H.; Run, E. C., \& Thurasamy, R. (2015). A Postura de Jovens Adultos Frente à Publicidade: uma análise multigrupo por etnias. Revista Brasileira de Gestão de Negócios, 17(54), 769-787.

Torres, C. (2009) A biblia do marketing digital: Tudo o que você queria saber sobre marketing e publicidade na Internet e não tinha a quem perguntar. São Paulo: Novatec.

Trindade, E.A (2009). publicidade e a crítica a sua produção de sentido no consumo. Revista Brasileira de Marketing, 8(2), 146-159.

Zuini, P. (2012). Quanto pequenas empresas devem investir em marketing. Revista Exame. AGO/2012. 